\title{
ANÁLISE DO IMPACTO DO PROGRAMA ENG200 NA CONSTRUÇÃO DE UM AMBIENTE FAVORÁVEL PARA MUDANÇAS EDUCACIONAIS
}

DOI: 10.37702/2175-957X.COBENGE.2021.3582

Alessandro Fernandes Moreira - moreira@cpdee.ufmg.br Universidade Federal de Minas Gerais Rua Dom Prudêncio Gomes 168 30535-580 - Belo Horizonte - MG

Karine Fernandes Brandão - karinebrandao8@gmail.com Universidade Federal de Minas Gerais Av. Pres. Antônio Carlos 6627

31270-901 - Belo Horizonte - MG

Ana Paula Pereira Theobald - anaptheobald@gmail.com Universidade Federal de Minas Gerais

Rua Martinica 432

31565-400 - Belo Horizonte - MG

Hanna Rodrigues - rdg.hanna@gmail.com

Universidade Federal de Minas Gerais

Rua llha Grande 300

31555-030 - BELO HORIZONTE - MG

Maria Luiza Coelho Rodrigues - malucrodriguess1@gmail.com Universidade Federal De Minas Gerais

Rua Mércia Siqueira Prates 39

31550-370 - Belo Horizonte - MG

Karenina Favoreto Pessi - karenina.favoreto@hotmail.com Universidade Federal De Minas Gerais

Rua Noraldino de Lima 290

31270-650 - Belo Horizonte - MG

Resumo: Este trabalho apresenta a análise do impacto do Programa de Inovação 
para Educação em Engenharia (Programa ENG200), criado em 2012 para construir um ambiente favorável para mudanças educacionais na Escola de Engenharia da UFMG (EEUFMG). A partir do o conceito de impacto, definido pela Organização para a Cooperação e Desenvolvimento Econômico (OCDE) como "efeitos de longo-prazo, positivos ou negativos, primários ou secundários, produzidos por uma intervenção de desenvolvimento, direta ou indiretamente, intencional ou involuntariamente", realizou-se uma pesquisa com discentes e servidores docentes e técnicos-administrativos da EEUFMG, por meio de formulários virtuais, com o objetivo de mensurar os impactos específicos de três projetos do Programa ENG200 (Engenharia Recebe, Projeto Desafio de Introdução à Engenharia e Ruptura UFMG), além dos impactos gerais do Programa. Os dados coletados a partir desses formulários são discutidos neste trabalho, buscando envolver todo o contexto que guiou o Programa em seus anos de atuação, bem como correlacionar essa atuação com a inovação, o protagonismo estudantil e as Diretrizes Nacionais Curriculares (DCNs) das Engenharias, norteadores do Programa ENG200.

Palavras-chave: Inovação e Empreendedorismo; Atividades Acadêmicas Complementares; Eventos de Educação; Inovação na Educação em Engenharia. 


\section{(C) COBENCE \\ 28 a 30 de SETEMBRO \\ ANÁLISE DO IMPACTO DO PROGRAMA ENG200 NA CONSTRUÇÃO DE UM AMBIENTE FAVORÁVEL PARA MUDANÇAS EDUCACIONAIS}

\section{INTRODUÇÃO}

O contexto de atuação dos engenheiros é tema de constantes mudanças desde o surgimento das primeiras escolas de engenharia. Até a década de 1980, a formação tecnicista era predominante. Entretanto, quando se percebeu que, além da ciência e tecnologia, algo mais era necessário na formação dos engenheiros, emergiu a necessidade de um profissional mais conectado com as demandas sociais e com as inovações e transformações tecnológicas vigentes. A partir dessas demandas naturalmente surge o questionamento de qual é o novo perfil de engenheiro pretendido.

A partir do início do Século XXI, grandes transformações ocorreram nos currículos de Engenharia. As Diretrizes Nacionais Curriculares (DCNs) de Engenharia de 2019 definiram o perfil pretendido para o egresso com características tais como: visão holística e humanista, ser crítico, reflexivo, criativo, cooperativo e ético e com forte formação técnica, adotar perspectivas multidisciplinares e transdisciplinares em sua prática, realizar a avaliação crítico-reflexiva dos impactos das soluções de Engenharia nos contextos social, legal, econômico e ambiental, comunicar-se eficazmente nas formas escrita, oral e gráfica (Resolução CNE/CSE 02/2019). O perfil do engenheiro que está sendo requerido exige mudanças no paradigma educacional, buscando uma formação com foco no estudante como sujeito contextualizado, dotado de inteligências múltiplas e que constrói o conhecimento em função de sua bagagem genética, cultural e social (PEREIRA, 2005).

Este trabalho apresenta a avaliação do impacto do Programa de Inovação para a Educação em Engenharia (Programa ENG200) na Escola de Engenharia da UFMG (EEUFMG), uma proposta pedagógica que vem sendo desenvolvida desde 2012 para criação de um ambiente favorável para mudanças educacionais. São destacados a relevância das atuações do Programa e como suas ações e projetos aproximam do perfil de egresso pretendido nas DCNs. Três projetos desenvolvidos pelo Programa ENG200 são avaliados: o Engenharia Recebe, o Projeto Desafio de Introdução em Engenharia e o Ruptura UFMG, alem do impacto geral do Programa.

\section{HISTÓRICO DO PROGRAMA ENG200}

A EEUFMG, desde 2011, tem analisado a sua realidade e se questionado sobre a formação ideal para seus discentes. A partir de referências internacionais, como a estrutura curricular dos cursos do Olin College of Engineering e a incubadora de projetos acadêmicos "The iFoundry" da University of Illinois at Urbana-Champaign, e projetos pedagógicos inovadores nacionais, como da Universidade Federal da Bahia e da Universidade Federal do ABC, a EEUFMG criou em 2012 o Programa ENG200, com o intuito de prover um ensino de excelência e condizente com os desafios do novo século. O Programa ENG200 tem como missão repensar a Educação em Engenharia, propondo avanços curriculares, estruturais e sociais, além de promover que os discentes consigam reconhecer as 
necessidades do meio em que vivem, desenvolver soluções e se tornarem profissionais mais alinhados ao perfil de egresso esperado (MOREIRA et al., 2013).

A visão do Programa ENG200 é pautada em uma educação que não apenas transfere o conhecimento, mas ajuda a criá-lo, e suas ações têm como propósito ajudar a comunidade acadêmica a enxergar o discente como agente ativo da sua própria história, pois a inteligência humana somente se desenvolve no indivíduo em função de interações sociais que são, em geral, negligenciadas (LA TAILLE, 1992 p. 11). O Programa ENG200 foi criado em 2012, quando a EEUFMG estava realizando os eventos de comemoração de seu centenário ocorrido em 2011. Naquela ocasião, objetivou-se "construir a Escola de Engenharia que queremos ter" no próximo centenário da EEUFMG. O Programa ENG200 atua a partir de duas frentes: (i) Formação, grupo de ações relacionadas com a formação dos discentes e incluem melhorias no currículo e na qualidade do ensino; e (ii) Estruturação, grupo de ações que visam melhorias na infraestrutura e na organização da EEUFMG. Tais frentes são englobadas por diversas atuações do Programa ENG200 e este trabalho analisa o impacto de 3 das principais ações e projetos desenvolvidos:

- Engenharia Recebe: evento de recepção dos calouros de Engenharia realizada no início de cada semestre letivo desde 2012, englobando atividades como: rodas de conversa com veteranos, introdução à atividades de extensão e gincana, proporcionando acolhimento e sentimento de pertencimento nos calouros;

- Projeto Desafio de Introdução à Engenharia: iniciado em 2013, caracteriza-se pela unificação das turmas de Introdução à Engenharia de 8 cursos de graduação. Fomentando o protagonismo estudantil, busca-se o desenvolvimento de projetos voltados para solução de problemas reais por meio da metodologia Design Thinking;

- Ruptura UFMG: evento de inovação e empreendedorismo no qual os participantes resolvem problemas reais de empresas, sendo capacitados por meio de palestras e mentorias. Com natureza disruptiva, o evento se reinventa a cada edição e promove uma sinergia entre o mercado de trabalho e universidade, gerando um ambiente favorável para troca de experiências.

O Programa ENG200 completará 10 anos em 2022 e deseja-se avaliar o seu impacto desde sua criação, para consolidação das ações e dos projetos desenvolvidos e também pelo momento em que deve ocorrer a avaliação do impacto, posto que essa análise é associada aos resultados de longo prazo, indo além de julgar apenas o que aconteceu após uma intervenção (COHEN; FRANCO, 2018 apud BAUER, 2010).

Nas seções seguintes, são apresentados a metodologia de análise e os resultados obtidos sobre o impacto do Programa ENG200 na EEUFMG. Adicionalmente, são destacadas a relevância das atuações do Programa para a EEUFMG e como as ações realizadas abrem espaços para o protagonismo estudantil, colocando o estudante como centro no processo de formação em Engenharia.

\section{METODOLOGIA DE ANÁLISE DO IMPACTO DO PROGRAMA ENG200}

A avaliação de um projeto pode envolver 4 etapas: análise da proposta, da implementação, dos resultados e dos impactos obtidos. Na análise da proposta, verifica-se a relevância do projeto e se o planejamento está adequado para atingir o objetivo préestabelecido. A análise da implementação verifica se o projeto está sendo conduzido de acordo com o seu planejamento. A análise dos resultados avalia se o projeto atingiu os objetivos pré-definidos e, por fim, a análise dos impactos avalia os resultados e efeitos da 
intervenção do programa a longo prazo (BAUER, 2010). Não existe um consenso entre os autores que discorrem sobre avaliação de impacto acerca dessas etapas, especialmente em relação à distinção da análise de resultados e de impactos. Alguns autores consideram resultados e impacto sinônimos, como Michael Scriven (1991 apud Adriana Bauer, 2010), que define a avaliação de impacto como uma avaliação focada nos resultados ou retornos dos investimentos, em vez de no processo, na entrega ou na avaliação da implementação. Neste trabalho, adotou-se o conceito de impacto definido pela Organização para a Cooperação e Desenvolvimento Econômico (OCDE): "efeitos de longo-prazo, positivos ou negativos, primários ou secundários, produzidos por uma intervenção de desenvolvimento, direta ou indiretamente, intencional ou involuntariamente" (OCDE, 2008). Com esta definição, há duas premissas: (i) atribuição, designando impactos a intervenções, em vez de apenas avaliar o que ocorreu; e (ii) contrafactual, na qual o conhecimento sobre os impactos produzidos por uma intervenção requer uma tentativa de aferir o que teria ocorrido na ausência da intervenção e a comparação com o que tem ocorrido com a realização da intervenção (LEEUW; VAESSEN, 2009, p.9).

Buscando avaliar os impactos do Programa ENG200 nos últimos 10 anos, realizouse uma pesquisa, entre 20 de março e 28 de abril de 2021, com discentes e servidores da EEUFMG. Essa pesquisa consistiu na elaboração de 5 formulários, com perguntas qualitativas e quantitativas, hospedados na plataforma Google, com o objetivo de mensurar os impactos específicos de 3 ações do Programa ENG200 (Engenharia Recebe, Projeto Desafio de Introdução à Engenharia e Ruptura UFMG), além dos impactos gerais do Programa. Os seguintes aspectos foram avaliados:

- Impacto do Engenharia Recebe: disponibilizado entre os discentes para mensurar se o sentimento de acolhimento e pertencimento à EEUFMG e o estabelecimento de vínculos com outros estudantes e iniciativas foram despertados, além de saber se os conhecimentos adquiridos nessa ação foram úteis para sua trajetória acadêmica;

- Impacto do Projeto Desafio de Introdução à Engenharia: disponibilizado para os discentes a fim de avaliar se os participantes desenvolveram a habilidade de resolução de problemas, o trabalho em equipe e os conhecimentos na área de gestão de projetos utilizando a metodologia Design Thinking;

- Impacto do Ruptura UFMG: disponibilizado para os discentes com objetivo de avaliar se o participante conseguiu expandir o networking, compreender seu potencial transformador, aplicar conhecimentos adquiridos em sala de aula e quão importante e útil o evento é para a trajetória acadêmica e profissional;

- Impacto do Programa ENG200: disponibilizado para os discentes a fim de avaliar se os objetivos do Programa estão sendo atingidos e se há contribuição para a trajetória do respondente, bem como para o desenvolvimento das ações de inovação na EEUFMG;

- Impacto do Programa ENG200: disponibilizado para os servidores (docentes, técnicosadministrativos e contratados), para avaliar se os objetivos do Programa estão sendo atingidos e se há contribuição para a trajetória do estudante, na visão dos servidores, assim como para o desenvolvimento das ações de inovação na EEUFMG.

Os critérios utilizados pelos formulários caracterizaram-se como elementos abstratos, por serem relacionados a sentimentos, e por isso são mais difíceis de serem medidos de maneira direta (BARBOZA; CARVALHO; COSTA; NETO, 2013). Além disso, entende-se como complexa a avaliação dos efeitos que são dependentes de uma intervenção só, uma vez que questões relativas à inferência causal estão implícitas nessa avaliação (SULBRANDT, 1993 apud BAUER, 2010). Entretanto, segundo Costa (2011), a natureza do objeto e a característica a ser mensurada não são impedimentos para sua 
mensuração. Portanto, para facilitar a avaliação desses resultados, adotou-se a escala Likert nos questionários, visto que é o modelo mais utilizado na literatura (COSTA; JÚNIOR, 2014). Essa escala caracteriza-se por apresentar um conjunto de afirmações relacionadas à definição de um construto, para as quais os respondentes emitem seu grau de concordância (COSTA; JÚNIOR, 2014). A figura 1 mostra um exemplo dessa escala na mensuração de satisfação com um determinado serviço, em 5 pontos (quantidade de pontos utilizada nos formulários da pesquisa do Programa ENG200).

Figura 1 - Exemplos de escala de Likert

\begin{tabular}{|c|c|c|c|c|}
\hline \multicolumn{6}{|c|}{ ESTOU SATISFEITO COM O SERVICO RECEBIDO: } \\
\hline $\begin{array}{c}\text { Discordo } \\
\text { totalmente }\end{array}$ & $\begin{array}{c}\text { Discordo } \\
\text { parcialmente }\end{array}$ & $\begin{array}{c}\text { Não concordo } \\
\text { nem discordo }\end{array}$ & $\begin{array}{c}\text { Concordo } \\
\text { parcialmente }\end{array}$ & $\begin{array}{c}\text { Concordo } \\
\text { totalmente }\end{array}$ \\
\hline $\mathbf{1}$ & $\mathbf{2}$ & $\mathbf{3}$ & $\mathbf{4}$ & $\mathbf{5}$ \\
\hline
\end{tabular}

Fonte: Costa e Júnior, p.4, 2014.

A partir da análise dos formulários, realizou-se também um comparativo entre antes e depois da criação do Programa ENG200, para compreender o aspecto contrafactual de seu impacto na EEUFMG. Para tal comparação, levantou-se os seguintes desafios que levaram a criação do Programa ENG200 e das 3 ações escolhidas para análise:

- Programa ENG200: realizar ações de inovação que alcancem avanços curriculares, estruturais e também sociais, para formar o novo perfil de engenheiro;

- Engenharia Recebe: existência de uma desconexão entre o estudante ingressante e a EEUFMG, em que o calouro sente que não pertence à universidade desde o seu ingresso no ambiente acadêmico, o que pode levar ao aumento da evasão dos cursos;

- Projeto Desafio de Introdução à Engenharia: carência de uma atividade pedagógica com diferentes metodologias de ensino e de avaliação, que estimula a inovação e o empreendedorismo, além do papel social do novo perfil de engenheiro;

- Ruptura UFMG: distanciamento entre a Universidade e o mercado de trabalho, falta de projetos mais práticos para estudantes da graduação em que eles consigam compreender o seu papel transformador na sociedade.

\section{RESULTADOS E ANÁLISE DO IMPACTO DOS PROJETOS DO PROGRAMA ENG200}

\subsection{Análise do Impacto Geral do Programa ENG200}

O ensino é um processo amplo e complexo que envolve não apenas relações interpessoais, mas também a relação do estudante com o ambiente. Ao abordar a transformação na educação, é necessário que as mudanças englobem diversos aspectos da formação acadêmica e considerem todos os envolvidos no processo educacional.

Neste contexto de mudanças educacionais, o Programa ENG200 possui um caráter inovador desde sua estrutura: os projetos são executados por discentes, com mentorias docentes e apoio da Direção da EEUFMG, unindo instituição e estudantes. O Programa tem uma atuação abrangente na EEUFMG, conseguindo atingir tanto estudantes quanto servidores. O primeiro impacto do Programa ENG200 é conseguir implementar ações de inovação para diferentes faces na EEUFMG e, para verificar esse efeito, nos 2 formulários de Impacto do Programa ENG200, desenvolveu-se a seguinte pergunta: "Quanto você acredita que o Programa ENG200 contribui para a inovação na educação na EEUFMG?'. Dos 47 respondentes que conhecem o Programa (Figura 2), seus objetivos e/ou suas 
ações, $74,4 \%$ responderam que concordam totalmente ou concordam com a contribuição, $17 \%$ que nem concordam nem discordam, 6,38\% que discordam e 2,12\% que discordam totalmente. A partir da análise dos dados coletados, entende-se que para a comunidade acadêmica da EEUFMG que conhece o Programa ENG200, há um impacto significativo à frente da inovação no ensino de engenharia na EEUFMG. Tal impacto está de acordo com a principal razão para a criação do Programa ENG200: prover um ensino de excelência e condizente com os desafios do novo século através da inovação. Ainda sobre o impacto de inovar na EEUFMG de maneira abrangente, destaca-se a quantidade de novas iniciativas estudantis que surgiram após a criação do Programa ENG200 em 2012 (Figura 3). Tal aumento ocorreu em função de atuações do Programa no mapeamento das iniciativas estudantis existentes na EEUFMG e na elaboração da resolução de atividades acadêmicas complementares para flexibilização curricular dos cursos da EEUFMG, que definiu quais atividades e a forma para integralização de créditos para formação complementar (MOREIRA et al., 2013).

Figura 2 - Avaliação do Programa ENG200 no quesito contribuição para a inovação na educação na Escola de Engenharia da UFMG.

Quanto você acredita que o Programa ENG200 contribui para a inovação na educação na Escola de Engenharia da UFMG?

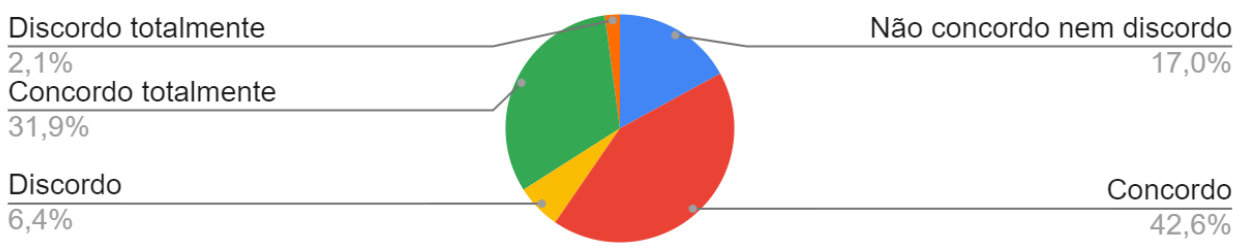

Fonte: Acervo dos Autores

Figura 3 - Número de iniciativas estudantis da EEUFMG desde 1990

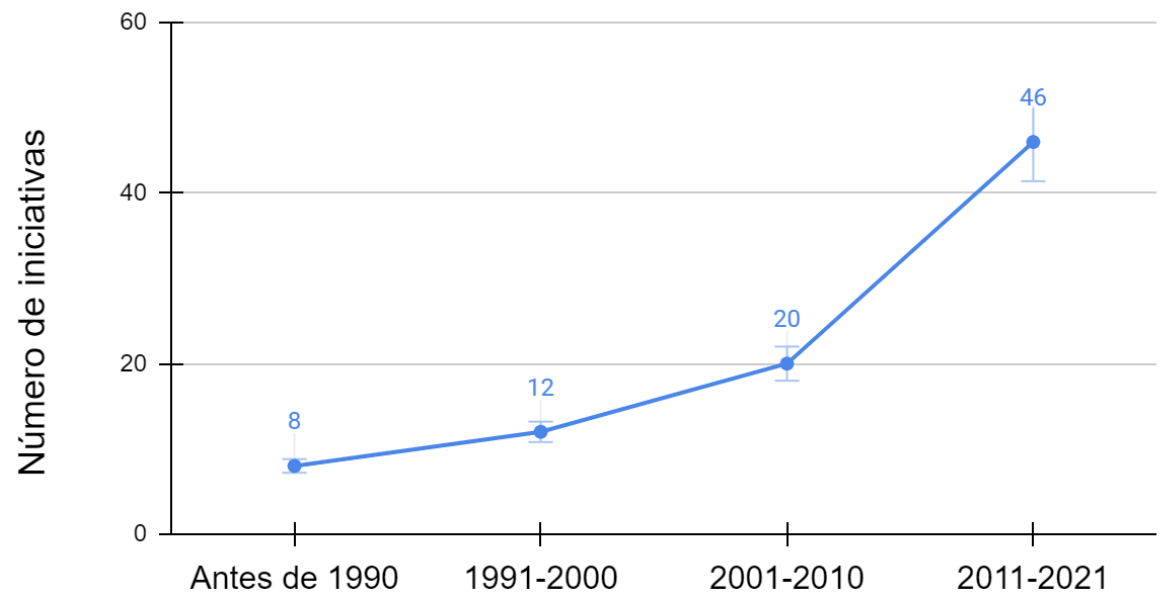

Período

Fonte: Acervo dos Autores

Outro impacto do Programa ENG200 passível de ser avaliado é a contribuição de suas ações e atuações para a trajetória acadêmica do estudante na EEUFMG, possibilitando tanto o aprendizado de novas habilidades quanto o surgimento de novas oportunidades. Nos dois formulários de Impacto do Programa ENG200, desenvolveu-se as seguintes perguntas: (1) "Quanto você acredita que o Programa ENG200 contribuiu até o 
momento para a sua trajetória acadêmica?', quando o respondente era um discente e (2) "Quanto você acredita que o Programa ENG200 contribuiu até o momento para a trajetória acadêmica dos estudantes da EEUFMG?' para os respondentes que são servidores da EEUFMG. Dos 47 respondentes que conhecem o Programa (Figura 4), 29,79\% responderam que "Contribuiu significativamente", 48,93\% que "Contribuiu parcialmente", $10,64 \%$ que "Contribuiu pouco" e 10,64\% que "Não contribuiu". O seguinte depoimento discente foi realizado no formulário Impacto do Programa ENG200:

"A partir do Ruptura pude entrar como associado no grupo LeanStartup da Wabtec, como voluntário, fiz visita técnica e participei de alguns webinares e treinamentos que me colocam em ambientes cada vez mais desafiadores. Como sou da Eng. Ambiental, tenho uma grande expectativa de conseguir ingressar na empresa, como estagiário, e realmente colocar as ideias desenvolvidas na graduação em prática[...]."

Figura 4 - Avaliação do impacto do Programa ENG200 no quesito contribuição para a trajetória acadêmica

Quanto você acredita que o Programa ENG200 contribuiu até o momento para a sua trajetória acadêmica?

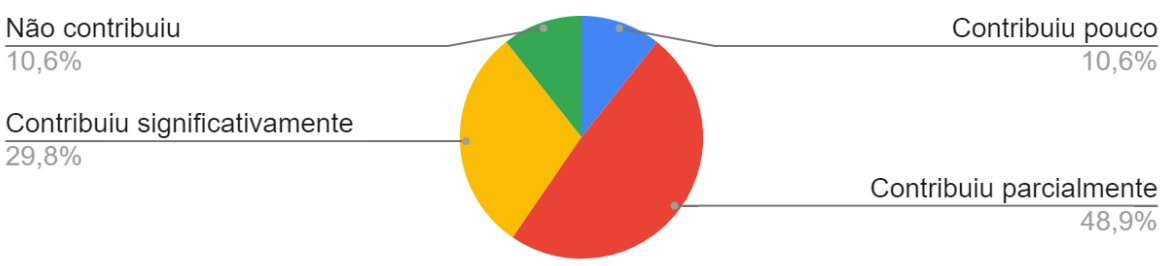

Fonte: Acervo dos Autores

Compreende-se que as ações do Programa ENG200 impactam positivamente na trajetória do estudante em diferentes períodos dos cursos. Por fim, ressalta-se que apenas 47 das 81 pessoas que responderam os dois formulários analisados conheciam os objetivos e as ações do Programa, sendo necessário um trabalho mais incisivo na divulgação da marca, visto que das 34 pessoas que afirmaram "Não conheço muito, mas já ouvi falar do Programa ENG200 e sobre suas ações" e "Não, nunca ouvi falar do ENG200", 20 marcaram conhecer ou ter participado de alguma ação do Programa.

\subsection{Análise do Impacto do Engenharia Recebe}

Partindo para uma visão mais segmentada do Programa ENG200, objetivou-se entender o impacto do Engenharia Recebe e uma análise comparativa entre o evento presencial, realizado entre 2012 e 2020/1, e o evento online, executado em 2020/2. Essa comparação justifica-se pela intenção de compreender o sentimento de pertencimento e acolhimento dos calouros à EEUFMG quando realizada uma recepção presencial e quando realizada de forma totalmente online. Em relação ao sentimento de acolhimento mensurado pela pergunta "Participando do evento enquanto calouro(a), você se sentiu acolhido pela Escola de Engenharia?' (Figura 5), dos 72 respondentes que participaram da ação, 81,9\% concordam totalmente ou concordam que o Engenharia Recebe proporciona tal pertencimento. Por outro lado, realizando um cruzamento de dados para compreender melhor as respostas, constatou-se que $78,57 \%$ dos calouros que participaram da versão online responderam "concordo totalmente" ou "concordo", contra 84,09\% dos estudantes que participaram presencialmente da recepção. A diferença de 5,52\% parecer pequena, 
porém corrobora com a tese de que, caso o Engenharia Recebe não fosse executado, o sentimento de acolhimento dos estudantes diminuiria, visto que atividades que geram a sensação de acolho, como a visita guiada pela EEUFMG, o apadrinhamento de calouros e a apresentação das iniciativas estudantis, foram prejudicadas com a mudança de formato da recepção de presencial para online.

Figura 5 - Avaliação do impacto do Engenharia Recebe no quesito acolhimento dos calouros da EEUFMG Participando do evento enquanto calouro(a), você se sentiu acolhido pela Escola de Engenharia?

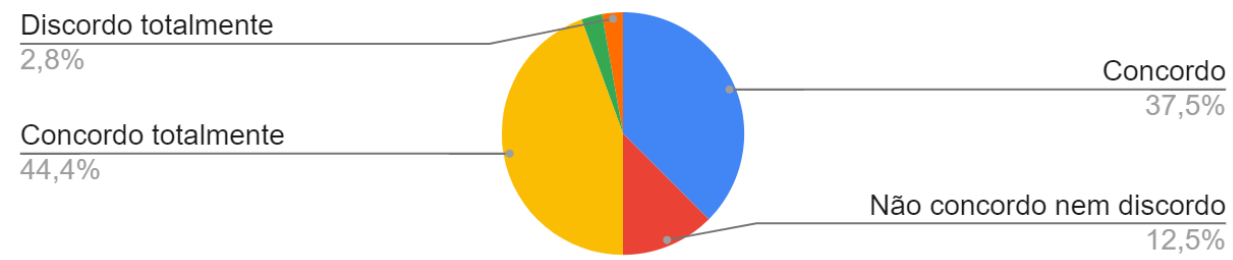

Fonte: Acervo dos Autores

A partir das respostas obtidas na pergunta "Após participar do evento enquanto calouro(a), quão pertencido(a) você se sentiu na Escola de Engenharia?', nota-se também as mesmas constatações apresentadas para o sentimento de acolhimento, dando destaque especial à relação de causa e efeito: o Engenharia Recebe (causa) impacta positivamente o sentimento de pertencimento (efeito) dos calouros à EEUFMG. Dos 72 respondentes que participaram da recepção (Figura 6), 63,9\% sentiram-se "Extremamente pertencido(a)" ou "Muito pertencido(a)", e 14,28\% dos participantes na versão online afirmaram se sentirem "Pouco pertencido(a)" ou "Nem um pouco pertencido(a)" contra 9,09\% daqueles que participaram presencialmente. Compreende-se que o Engenharia Recebe repercute no sentimento de acolhimento e pertencimento à EEUFMG de maneira positiva nos calouros. Este impacto também pode ser observado por depoimentos anônimos que foram expostos no formulário:

"A iniciativa sem dúvida merece muito louvor, cada dinâmica entre calouros e veteranos da EE faz muita diferença para o primeiro contato com a universidade. Sou muito grata em ter participado do engenharia recebe quando caloura [..]" "Eu vim de SP e achei muito bacana o evento, fui super acolhido, mesmo a distância [..]"

Figura 6 - Avaliação do impacto do Engenharia Recebe no quesito pertencimento à EEUFMG

Após participar do evento enquanto calouro(a), quão pertencido(a) você se sentiu na Escola de Engenharia?

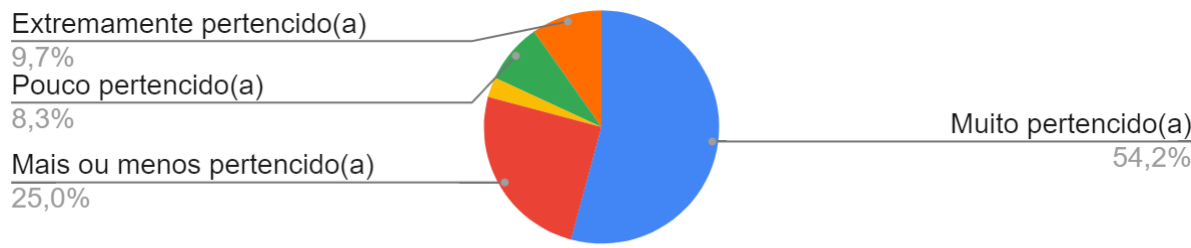

Fonte: Acervo dos Autores

\subsection{Análise do Impacto do Projeto Desafio de Introdução à Engenharia}

Prosseguindo na análise, o Projeto Desafio de Introdução à Engenharia tornou-se 
objeto para avaliação de impacto do Programa ENG200, a partir de perguntas relacionadas a equipes multidisciplinares e uso de metodologias ativas: (1) "Quão importante é para você participar de uma atividade acadêmica com grupos multidisciplinares durante a faculdade?' e (2) "Quão importante é para você participar de uma atividade acadêmica que utiliza metodologias ativas de ensino durante a faculdade?" Para a pergunta 1 (Figura 7), dos 222 respondentes, 73,4\% afirmaram que é "Extremamente importante" ou "Muito importante", enquanto 16,2\% responderam "Mais ou menos importante", 7,7\% pontuaram ser "Pouco importante" e 2,7\% consideram ser "Nem um pouco importante". A partir desse levantamento, nota-se que, por parte dos estudantes, há uma valorização do trabalho em grupo e do contato com pessoas de diferentes cursos, como é feito na ação do Programa ENG200. Apesar disso, pontua-se, por parte dos estudantes, que em razão do Projeto Desafio de Introdução à Engenharia ser realizado no primeiro período dos diferentes cursos de engenharia, a multidisciplinaridade não é totalmente explorada, como citado neste depoimento:

"Acho muito importante porém não da forma como é feito no desafio, não vejo sentido em formar grupos de diversos cursos no primeiro semestre. Todos ali estão no ciclo básico cursando pouquíssimas ou nenhuma matéria específica da área de cada curso. Em virtude disso, ninguém tem nada a agregar em relação a conhecimentos específicos nesse momento curso[...]."

Figura 7 - Avaliação do impacto do Desafio de Introdução à Engenharia no quesito percepção dos discentes em relação à necessidade de multidisciplinaridade em sua trajetória acadêmica

Quão importante é para você participar de uma atividade acadêmica com grupos multidisciplinares durante a faculdade?

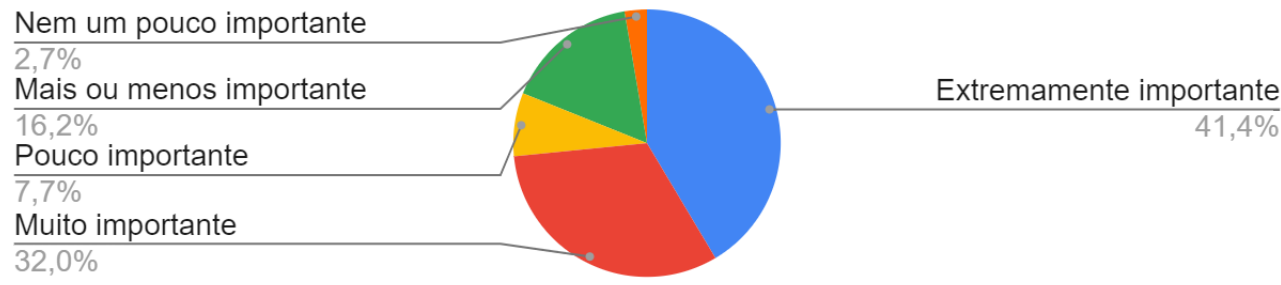

Fonte: Acervo dos Autores

Percebe-se que ainda é necessário fomentar o ideal de que mesmo estudantes do primeiro semestre, por serem de diferentes engenharias, possuem perfis diferentes e que por isso a multidisciplinaridade no primeiro período permanece válida e é essencial para a formação do novo perfil de egresso estabelecido pelas DCNs de Engenharia.

Para a pergunta 2 (Figura 8), dos 222 respondentes, 86\% afirmaram ser "Extremamente importante" ou "Muito importante", contra 9\% que responderam "Mais ou menos importante", 1,8\% que consideram ser "Pouco importante" e 3,2\% que pontuaram ser "Nem um pouco importante". Outro impacto importante do Programa ENG200 é proporcionar, no primeiro período de 8 cursos de engenharia, um projeto que utiliza metodologias ativas de ensino e incentiva o estudante enquanto principal agente do seu próprio processo de aprendizagem. Contudo, foi pontuado que a utilização de metodologias ativas não deve ser apenas recorrente em poucas disciplinas, mas sim uma construção de maneira gradativa por diferentes frentes, como abordado anonimamente:

"Acredito que seja sim importante criar uma independência dos alunos para com os professores, mas também acho que toda mudança deve ser um processo e não uma imposição, portanto deixar alunos recém integrados a 
instituição e que além das obrigações normais de estudante ainda tem que lidar com a adaptação a uma nova realidade com mais responsabilidades torna a iniciativa não eficiente em alguns aspectos."

Figura 8 - Avaliação do impacto do Desafio de Introdução à Engenharia no quesito percepção dos discentes em relação à importância da utilização de metodologias ativas no ensino

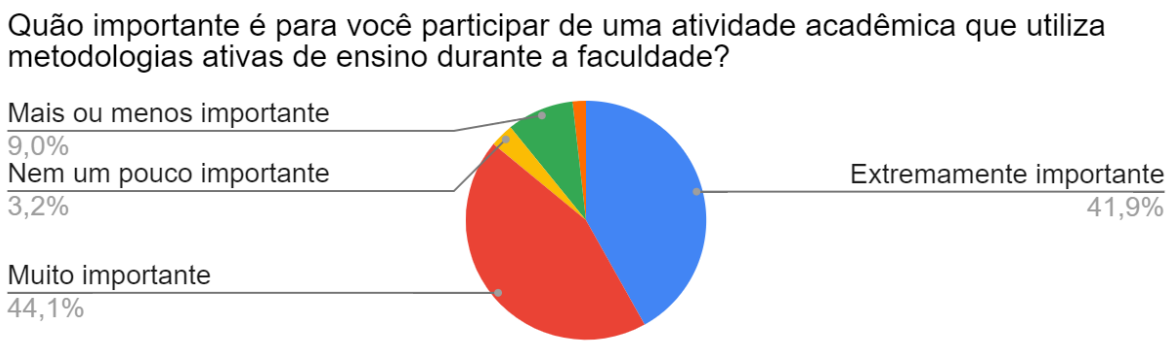

Fonte: Acervo dos Autores

Constata-se que a utilização de metodologias ativas para fomentar o estudante como principal autor de sua trajetória acadêmica possui um impacto positivo na visão dos discentes, embora urge expandir esse método em toda a EEUFMG, não somente em poucos projetos, como o Projeto Desafio de Introdução à Engenharia. Portanto, ressalta-se a necessidade de uma transformação no ensino em conjunto, e não individual, em que o Programa ENG200 objetiva ser o precursor de inovações na EEUFMG, mas que, ao mesmo tempo, tais inovações sejam disseminadas pela Escola, sendo assim um agente responsável pela construção de um ambiente para mudanças educacionais, a fim de formar engenheiros com o novo perfil pretendido.

\subsection{Análise do Impacto do Ruptura UFMG}

Finalizando a avaliação de impacto do Programa ENG200, analisou-se o evento Ruptura UFMG. Nessa análise, para avaliar a aproximação da Universidade com o mercado de trabalho e a autocompreensão do potencial transformador do estudante, perguntou-se: (1) "Participando do evento, você conseguiu compreender seu potencial transformador?' e (2) "Quão importante é para você participar de um evento que possibilita contato com o mercado de trabalho?'. Para a pergunta 1 (Figura 9), dos 46 respondentes que participaram do evento, $73,9 \%$ afirmaram que concordam totalmente ou concordam que o evento Ruptura UFMG propiciou a compreensão do potencial transformador do participante, enquanto $13 \%$ responderam que não concordam nem discordam, 10,9\% pontuaram discordar e 2,2\% discordaram totalmente. Fundamentado nos dados da figura 9, nota-se 0 impacto positivo do Programa ENG200, por meio do evento Ruptura UFMG, de incentivar que estudantes assimilem seu potencial transformador em diversas áreas, como a sociedade, o mercado de trabalho e a Universidade. Essa compreensão apresenta-se como fundamental para que os universitários procurem modificar e melhorar o seu entorno, criando novos processos e buscando novas soluções para aqueles já existentes. Para a pergunta 2 (Figura 10), dos 46 respondentes, 52,2\% relataram ser "Extremamente importante", 43,5\% consideram ser "Muito Importante" e 4,3\% responderam ser "Mais ou menos importante", nenhum respondente afirmou ser "Pouco importante" ou "Nem um pouco importante". 
Figura 9 - Avaliação do impacto do Ruptura UFMG no quesito conscientização dos discentes quanto ao seu potencial transformador

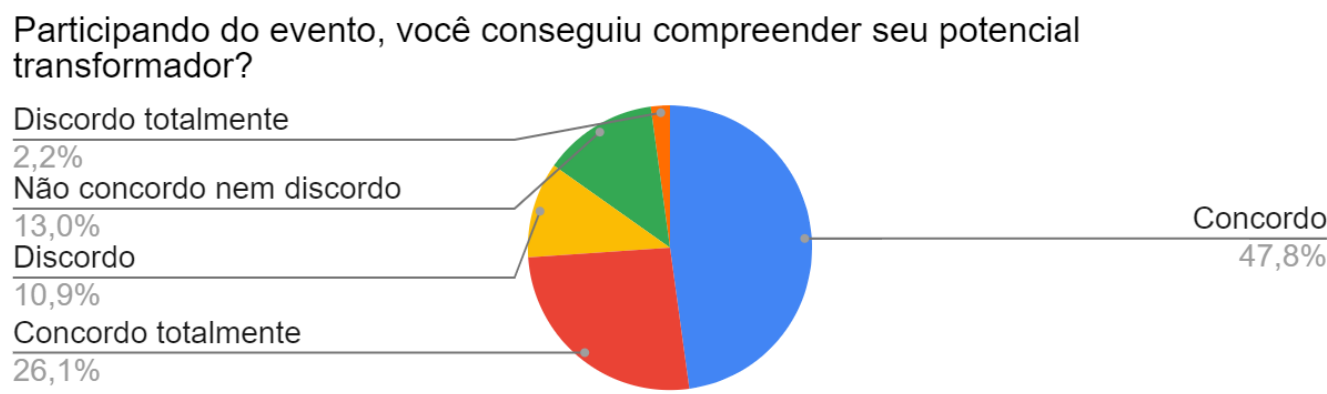

Fonte: Acervo dos Autores

Figura 10 - Avaliação da necessidade de eventos que possibilitem o contato do participante com o mercado de trabalho

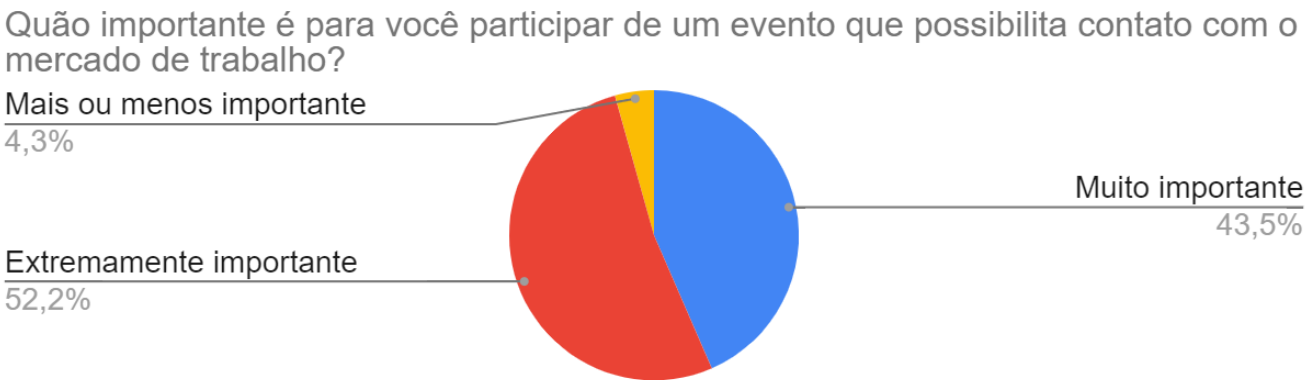

Fonte: Acervo dos Autores

O Ruptura UFMG tem o impacto positivo de aproximar estudantes e mercado de trabalho, visto que o evento conta com a participação de empresas que ministram workshops e treinamentos, além de hackathons com casos reais. Esta aproximação é considerada benéfica pelos estudantes, como mencionado neste depoimento:

"O contato com o mercado de trabalho - seja com quem propõe os cases, seja com os mentores, etc - é importantíssimo na formação de qualquer estudante. Ainda que busque uma carreira acadêmica, entender as frustrações e desafios do mercado é um grande direcionador para linhas de pesquisa. Para quem tem interesse prático, quanto mais cedo acontecer a exposição, melhor, dando mais sentido ao que se estuda e direcionando melhor a pessoa no que tange às skills (hard e soft) que ela precisa desenvolver. Sem contar na criação de network forte e com alto potencial."

À vista desses resultados, compreende-se que o Programa ENG200 propicia um evento de inovação e empreendedorismo que permite a formação de características necessárias para o novo perfil de egresso, como por exemplo, a capacidade de realizar uma avaliação crítico-reflexiva do engenheiro sobre os impactos das soluções de Engenharia nos contextos social, legal, econômico e ambiental.

\section{CONSIDERAÇÕES FINAIS}

O Programa ENG200 foi criado durante as comemorações do centenário da EEUFMG e possui a missão de construir a Escola de Engenharia que se deseja ter nos próximos 100 anos. A partir do amadurecimento do Programa ENG200 durante seus 9 anos de existência e à vista do seu propósito inovador, surgiram questionamentos: o Programa 
ENG200 está atingindo seus objetivos? Quais impactos do Programa ENG200 podem ser mensurados durante esse período?

Por meio da pesquisa apresentada neste trabalho, conclui-se que o Programa ENG200 possui um impacto positivo na EEUFMG. Entretanto, ressalta-se que devido ao curto período de tempo de realização da pesquisa, a quantidade de respondentes em comparação ao público-alvo foi pequena, porém com resultados expressivos dentre os respondentes. Para a análise do impacto do Engenharia Recebe, coletou-se a opinião de 72 pessoas, enquanto a média de calouros participantes da recepção é de 200 pessoas. Ademais, para verificar o impacto do Projeto Desafio de Introdução à Engenharia, reuniuse a posição de 222 pessoas enquanto o número de calouros por semestre é cerca de 400 . No formulário de impacto do Ruptura UFMG, obteve-se 46 respostas contra a média de 150 participantes por evento. Por fim, para os formulários de impacto do Programa ENG200 aplicados em cerca de 500 funcionários e cerca de 5.000 estudantes, atingiu-se 81 respostas, porém apenas 47 respondentes conheciam o Programa ENG200. Portanto, é necessário ampliar o número de respostas obtidas para avaliar mais precisamente o impacto do Programa ENG200, que será objeto de pesquisas futuras.

As ações do Programa ENG200, sempre alinhadas às DCNs de Engenharia, cumprem seus objetivos, voltados para a disseminação de aprendizagem ativa, inovação, empreendedorismo e multidisciplinaridade. Perguntas como "Participando do evento enquanto calouro(a), você se sentiu acolhido pela Escola de Engenharia?' e “Após participar do evento enquanto calouro(a), quão pertencido(a) você se sentiu na Escola de Engenharia?', que obtiveram respostas majoritariamente positivas, mostram uma preocupação do Programa ENG200 com o acolhimento estudantil, um conceito que só foi explorado pelas DCNs em 2019, mas que o Programa ENG200 trabalha desde 2012.

Conclui-se que o Programa ENG200 não é apenas moderno e inovador, mas também pensa no futuro. Assim como Paulo Freire já reconhecia que "Ensinar exige consciência do inacabamento" (FREIRE, 2002, p. 21), o Programa ENG200 similarmente reconhece a necessidade de procurar o aperfeiçoamento contínuo e está sempre se atualizando conforme as necessidades do contexto no qual está inserido.

\section{REFERÊNCIAS BIBLIOGRÁFICAS}

BAUER, A. Avaliação de impacto no Brasil: é possível mensurar impactos de programas de formação docente? Estudos em Avaliação Educacional, v. 21 n. 46, p. 229-251, 2010.

BARBOZA, S. I. S.; CARVALHO, D. L. T.; SOARES NETO, J. B.; COSTA, F. J. Variações de mensuração pela escala de verificação: uma análise com escalas de 5, 7 e 11 pontos. Teoria e Prática em Administração, v. 3, n. 2, p. 99-120, 2013.

CONSELHO NACIONAL DE EDUCAÇÃO. Resolução CNE/CSE 02/2019: Institui Diretrizes Curriculares Nacionais do Curso de Graduação em Engenharia. Diário Oficial da União, Brasília, 09 de abril de 2002. 26 de abril de 2019, Seção 1, p. 43-44.

COSTA, Francisco. Mensuração e Desenvolvimento de Escalas: Aplicações em Administração. Rio de Janeiro: Ciência Moderna, 2011. 
FREIRE, Paulo. Pedagogia da Autonomia. 25. ed, São Paulo: Paz e Terra, 2002.

LA TAILLE, Yves de.; OLIVEIRA, Marta Kohl; DANTAS, Heloysa. Piaget, Vygotsky, Wallon: teorias psicogenéticas em discussão. São Paulo: Summus. 1992.

LEEUW, F.; VAESSEN, J. Impact evaluations and development: NONIE'S guidance on impact evaluation. Washington: World Bank. 2009.

MOREIRA, Alessandro F. et al. Práticas Pedagógicas Integradoras e Tecnologias para o Ensino de Engenharia: Programa de Inovação na Educação em Engenharia. In: OLIVEIRA, Vanderli $F$. et al. DESAFIOS DA EDUCAÇÃO EM ENGENHARIA: Formação em Engenharia, Capacitação Docente, Experiências Metodológicas e Proposições. 1a. ed. Porto Alegre: Ed. Forma Diagramação, 2013, v. 1, p. 215-226.

OECD. Draft NONIE statement on impact evaluation. Disponível em: https://www.oecd.org/development/evaluation/dcdndep/40104352.pdf Acesso em: 15 de abril de 2021.

PEREIRA, M. A. Ensino-Aprendizagem em um Contexto Dinâmico. São Paulo: Universidade de Engenharia São Carlos, 2005. 129 p. Tese Doutorado.

SILVA, D. S.; COSTA, J. F. Mensuração e Escalas de Verificação: uma Análise Comparativa das Escalas de Likert e Phrase Completion. Revista Brasileira de Pesquisas de Marketing, Opinião e Mídia. v. 7, n. 2, 2014.

\section{ANALISYS OF THE ENG200 PROGRAM INFLUENCE ON THE BUILDING OF A FAVORABLE ENVIRONMENT FOR EDUCATIONAL CHANGES}

Abstract: This paper presents the analysis of the influence of the Innovation Program for Engineering Education (ENG200 Program), founded in 2012 to build a favorable environment for educational changes at the School of Engineering of UFMG (EEUFMG). Based on the concept of impact, defined by the Organization for Economic Cooperation and Development (OECD) as "long-term effects, positive or negative, primary or secondary, produced by a development intervention, directly or indirectly, intentionally or involuntarily", a survey was carried out with EEUFMG students, faculty and technical-administrative staff, through online forms, with the objective of measuring the specific impacts of three ENG200 Program projects (Engenharia Recebe, Challenge Project of Introduction to Engineering and Ruptura UFMG), in addition to the general influences of the Program. The data collected from these forms are discussed in this paper, seeking to involve the entire context that guided the Program in its years of operation, as well as to correlate its performance with innovation, student leadership and the National Curricular Guidelines (DCNs) of Engineering, guiding principles of the ENG200 Program.

Keywords: Engineering Education; Curriculum Innovation; Student Leadership; Impact of Educational Projects. 